\title{
The Combustion Characteristics of Waste Liquor from Renewable Plant-Derived Chemical Polyol Processing
}

\author{
Dawei WANG ${ }^{1,2}$, Guangbo ZHAO $^{1}$, Yuting LI ${ }^{1}$, Yigang LUAN ${ }^{3 *}$ \\ ${ }^{1}$ School of Energy Science and Engineering, Harbin Institute of Technology, 92 West Da Zhi Str., Harbin 150001, \\ Heilongjiang, China \\ ${ }^{2}$ Wuhan Boiler Group Co., Ltd, No.1 Jiangxia Avenue, Miaoshan Development District, Wuhan 430070, Hubei, China \\ ${ }^{3}$ College of Power and Energy Engineering, Harbin Engineering University, Room 1002 Power Building No.145 Nantong \\ Str., Harbin 150001, Heilongjiang, China
}

crossref http://dx.doi.org/10.5755/j02.ms.22497

Received 14 January 2018; accepted 06 May 2019

\begin{abstract}
An experimental study was carried out to investigate the combustion characteristics of plant-derived polyol liquor waste using thermogravimetric analyzer and vertical tube furnace tests. The research results showed that the waste liquor combustion reaction comprised four processes: evaporation, pyrolysis, combustion, and inorganic salt reaction, and that a wave peak exists for each process. The pyrolysis process, which is the most violent reaction, exhibited the maximum peak weight-loss rate and weight-loss ratio and had the lowest activation energy and frequency factor. The peak weight-loss rate of inorganic salt reaction process was less than that during the combustion process, but sodium alkali has catalytic effect at high temperature, which makes the activation energy and the frequency factor of inorganic salt reaction process less than that of the combustion process. The ignition temperature of the waste liquor in the vertical tube furnace was lower than the temperature in the thermogravimetric analyzer. The ignition temperature of pyrolysis volatiles measured in a vertical tube furnace was less than $700^{\circ} \mathrm{C}$ but the ignition temperature of carbon combustion as measured with TG DTG was $718{ }^{\circ} \mathrm{C}$. When the temperature inside vertical tube furnace was higher than $800{ }^{\circ} \mathrm{C}$, the waste liquor combustion process becomes almost instantaneous (about $8 \mathrm{~s}$ ) and is violent, which produces more residual carbon content in the combustion products as a longer holding time is necessary to ensure that the reaction is completed.

Keywords: plant chemical polyol, waste liquor, kinetics, combustion, evaporation, pyrolysis, inorganic salt reaction.
\end{abstract}

\section{INTRODUCTION}

When properly exploited, renewable resources can have advantages of low pollution, low emissions and a continuing source of supply. In consequence, renewable resources are receiving considerable recent attention [1]. Biomass is an important renewable resource and, in order to replace fossil resources such as petroleum, all the major energyconsuming countries are actively exploring and researching the production of energy and the extraction of useful materials from biomass to produce plant-based chemical products and raw materials [2, 3].

A great deal of researches and development has been carried out on the bio-refining of corn and corn straw to produce polyols for industrial applications [4]. Bio-refining has particular advantages of low energy consumption and low emissions. The bio-refining production of glycols directly reduces carbon dioxide emissions by $51.7 \%$, compared to petroleum refining. It takes 1.42 tons of corn to produce 1 ton of glycol, 4.54 tons of carbon dioxide is absorbed during growth of the corn, 2.55 tons carbon dioxide is released during bio-refining and 1.99 tons of the carbon dioxide from the corn is transformed into glycol [5]. The development of renewable plant-derived chemical polyol technology has positive practical and social significance preference to avoid petroleum resources and reduce environmental pollution and has a far-reaching impact on the development of an economically sustainable ecological environment [6].

A large amount of waste liquor will be produced in the process of production plant-derived chemical polyol. If it is not be treated in a timely manner, the waste will result in serious pollution to the natural environment. In consequence, pollution-free treatment of the waste liquor has become the key restriction to the development of the plant-based chemical polyol industry [7].

The waste liquor from the plant-based polyol process has similar characteristics the black liquor produced during papermaking and therefore industry can learn lessons from the black liquor treatment approach. The combustion of black liquor is a mature and effective way to recover the thermal energy of the waste liquor and produce inorganic sodium salts that can be recycled and reused [8]. The combustion process of black liquor can be considered in four stages: drying, pyrolysis carbon combustion, and inorganic salt reduction, though each stage is not isolated, and all stages may occur simultaneously in a continuous process unit $[9,10]$. References by Hupa et al to the four stages of black liquor combustion have been widely recognized in this field [11-13].

Nassar [14] studied the combustion characteristics of black liquor of bagasse pulp using a thermogravimetric analyzer. It was shown that there are three active peaks at $50{ }^{\circ} \mathrm{C}, 273{ }^{\circ} \mathrm{C}$, and $670{ }^{\circ} \mathrm{C}$, and it is considered that

\footnotetext{
* Corresponding author. Tel.: +8 613845053255 .

E-mail address: shandong-313@163.com (Y. Luan)
} 
volatilization and vulcanization of organic matter occur at a lower temperature. Decomposition of the organic matter occurs during pyrolytic combustion at a higher temperature and the inorganic salt reaction takes place later at higher temperatures $\left(800 \sim 1000{ }^{\circ} \mathrm{C}\right)$.

Hupa et al. [9, 15] utilized a $1 \sim 2 \mathrm{ml}$ black liquor droplet in a high temperature reactor at $800{ }^{\circ} \mathrm{C}$ for their combustion tests. It was found that the initial size of the droplet was basically unchanged. After $1 \sim 2 \mathrm{~s}$ a yellow flame appeared, and the droplet entered the pyrolysis stage. The droplet size then expanded rapidly. It was found that the inner hollow coke particles burned more rapidly than the homogeneous particles. The hollow structure increases the specific surface area, which enables better internal mass transfer and more rapid heat transfer [16].

The temperature, particles size and weight of black liquor droplets change in the combustion process. The surface temperature of the droplets in the combustion always is greater than the internal temperature. It tends to be consistent in the later stage of the coke combustion reaction. There are coincidences in each reaction stage, and it is difficult to strictly distinguished, the process of mass transfer and heat transfer is uneven [17, 18]. The lignin and sodium salts in black liquor have an important influence on the pyrolysis and combustion performance [19]. The stage of lignin pyrolysis will release a large amount of volatile gas, which promotes the thermochemical reaction of black liquor [20]. Most of the research into plant-derived chemical polyol is at the stage of exploration or pilot testing. Research into the handling of the waste liquor stream has only recently commenced. In the present investigation, the combustion characteristics of plant-derived chemical polyol waste liquor were studied through experimental tests and theoretical analysis methods in order to provide background information on which to base further research on the study of waste liquor combustion technology.

\section{TEST SAMPLES AND METHODS}

\subsection{Samples}

Samples of plant-derived chemical polyol waste liquor were obtained from a pilot production plant with an annual output of 200,000 tons of polyol. The waste liquor is a very complex multi-component material with a density $\rho=1.1669 \mathrm{~g} \cdot \mathrm{ml}^{-1}$.

As a by-product of the production process, the plantderived chemical polyol waste liquor is creamy at room temperature and is brown, with rapidly decreasing viscosity, at higher temperatures. When the liquor was heated to $100{ }^{\circ} \mathrm{C}$, the dynamic viscosity decreased to $210 \mathrm{CP}$, which exhibits good fluidity.

The components of the plant-derived chemical polyol waste liquor can be simplified to $\mathrm{C} 15 \mathrm{H} 37 \mathrm{O} 8 \mathrm{Na} \cdot 3 \mathrm{H} 2 \mathrm{O}$ and the product after combustion of the waste liquor was carbon dioxide water, sodium carbonate, and other minor components. The main reaction formula can be summarized as follows:

$$
\begin{aligned}
& \mathrm{C}_{15} \mathrm{H}_{37} \mathrm{O}_{8} \mathrm{Na} \cdot 3 \mathrm{H}_{2} \mathrm{O}+20.5 \mathrm{O}_{2} \underset{\text { combustion }}{\longrightarrow} \\
& 14.5 \mathrm{CO}_{2}+21.5 \mathrm{H}_{2} \mathrm{O}+0.5 \mathrm{Na}_{2} \mathrm{CO}_{3}+7.98 \mathrm{MJ} / \mathrm{mol}
\end{aligned} .
$$

\subsection{Test methodology}

The test equipment consisted of a standard TGA/SDTA851e thermogravimetric analyzer system produced by Mettler-Toledo and a bespoke vertical tube furnace arrangement that was developed in-house. The thermogravimetric analyzer was utilized to conduct standard TG/DTG determinations and the vertical tube furnace was used to undertake combustion tests at sequential preset temperatures. The tube furnace configuration is shown in Fig. 1.

\subsubsection{Thermogravimetric analyzer}

The thermogravimetric analyzer was used to evaluate the dynamic combustion parameters of the plant-derived chemical polyol waste liquor. The thermogravimetric analyzer atmosphere was controlled to be air or nitrogen. The heating rate was $10^{\circ} \mathrm{C} \mathrm{min}^{-1}$. The plant-derived chemical polyol waste liquor sample was heated from $50{ }^{\circ} \mathrm{C}$ to $950{ }^{\circ} \mathrm{C}$, and the air flowrate was $80 \mathrm{ml} \mathrm{min} \mathrm{m}^{-1}$. Alternatively, the nitrogen flow rate was $40 \mathrm{ml} \mathrm{min}^{-1}$. The weight of the test liquor droplet was controlled to be $\sim 5 \mathrm{mg}$. Pyrolysis tests under a nitrogen atmosphere were carried out in order to compare the results with others obtained from the combustion experiment in an air atmosphere.

\subsubsection{Vertical tube furnace test method}

The vertical tube furnace test simulated the reaction state of flowing droplets at high temperature and allowed the combustion process of waste liquor droplets to be observed and recorded by a high-speed camera. The test arrangement is shown in Fig. 1. The furnace was heated by a silicon molybdenum electrical resistance wire coil to temperatures up to $1800{ }^{\circ} \mathrm{C}$. An observation hole is provided in the furnace casing to allow a high-speed camera to capture the combustion behavior in the furnace. The inner diameter of the quartz tube in the center of the tube furnace was $54 \mathrm{~mm}$ and the length was $1045 \mathrm{~mm}$; the outer diameter of the ceramic tube was $30 \mathrm{~mm}$, the inner diameter was $22 \mathrm{~mm}$, and the length of the tube was $400 \mathrm{~mm}$.

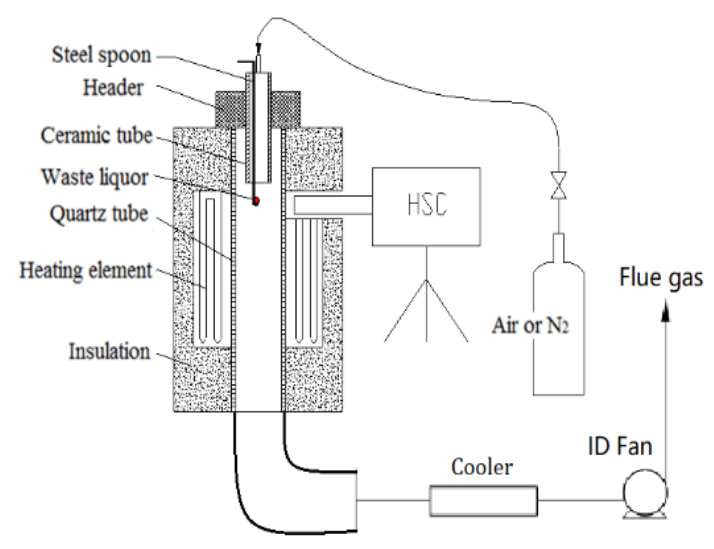

Fig. 1. Test system diagram of the vertical tube furnace

The upper section of the arrangement utilized a watercooled head and a ceramic fiber/rubber gasket was placed between the head and the quartz tube to seal the joint and provide a thermal break between the furnace tube and the head. 
The liquid droplets were placed in a stainless-steel metal spoon and suspended into the upper end of the ceramic tube into the furnace, exposing it to the hightemperature zone of the furnace to start the thermal degradation reaction. The ceramic tube is used to reduce the influence of the high-temperature furnace on heat radiation during the movement of the droplets and to prevent the reaction from occurring before the waste liquor is located in the designated position. The upper end of the ceramic tube is fitted with a rubber plug, and gas (air or nitrogen) is introduced from the upper end of the ceramic tube at a flow rate of $8 \mathrm{~L} / \mathrm{min}$. The gas introduced into the upper end of the ceramic tube not only ensures an oxidizing or inert atmosphere around the droplet but also functions to cool the ceramic tube and the sample. Before each test, air or nitrogen was injected into the furnace to give the desired atmosphere. The waste gas was discharged from the bottom of the reactor tube and exhausted to atmosphere.

In order to ensure that the preset temperature is reached in the furnace, high temperature insulation ceramic fiber is used to fill the upper and lower ends of the casing and any gap portions other than the observation port for heat preservation. The position of the observation port was set at a position of 26 to $31 \mathrm{~cm}$ from the top of the furnace. The temperature profile was calibrated every $1 \mathrm{~cm}$ into the furnace. The results of the temperature calibration plot at the observation port of the quartz tube are shown in Fig. 2. As is evident from this plot, the temperature required for the combustion tests was achieved in the vicinity of the position of the observation port.

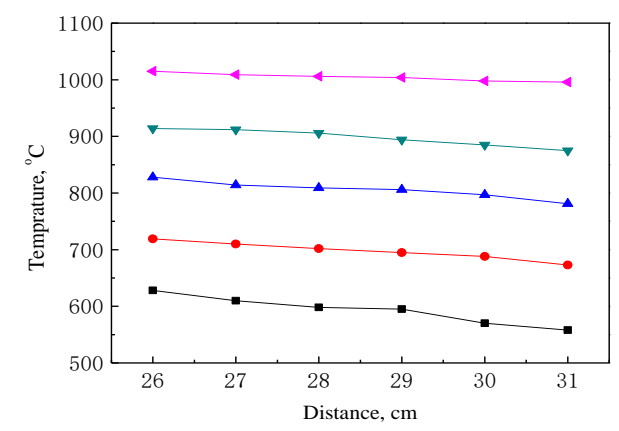

Fig. 2. Observation port temperature profile diagram

During each combustion test, a Cooke PCO.1200 s professional high-speed camera (HSC) produced by Cooke Co., Ltd. was used to record the reaction process of droplets in the furnace, and the exposure time was set to $50 \mathrm{~ms}$.

\subsection{Thermodynamic method}

The macromolecular compound decomposition dynamics study was carried out using the Coats-Redfern method, and the separation of the variable integrals is listed below [21-23]:

$$
\begin{aligned}
& \ln \frac{g(\alpha)}{T^{2}}=\ln \frac{A R}{\beta E}-\frac{E}{R} \times \frac{1}{T} ; \\
& g(\alpha)=\frac{1-(1-\alpha)^{1-n}}{1-n}(n \neq 1) ;
\end{aligned}
$$

$\alpha=\frac{m_{0}-m}{m_{0}-m_{\infty}}$,

where $A$ is the frequency factor, $\min ^{-1} ; E$ is the activation energy, $\mathrm{kJ} \cdot \mathrm{mol}^{-1} ; m, m_{0}, m_{\infty}$ is the quality when the heating temperature is $T$, the temperature at the start of heating, and the end of heating, $\mathrm{mg} ; n$ is the index, 0.5, 0.6, 0.7, 0.8, 1.2, $1.5 \ldots ; T$ is Kelvin temperature, $\mathrm{K} ; R$ is the molar gas constant, $8.314 \mathrm{~J} \cdot \mathrm{mol}^{-1} \cdot \mathrm{K}^{-1} ; \alpha$ is the quality change rate; $\beta$ is the heating rate, ${ }^{\circ} \mathrm{C} \mathrm{min}^{-1}$.

At a fixed heating rate, $\ln \frac{A R}{\beta E}$ is constant, used $\ln \frac{g(\alpha)}{T^{2}}$ and $\frac{1}{T}$ drawing.

After selecting an appropriate $\mathrm{n}$ value and performing straight line fitting for the slope, $-\frac{E}{R}$ is obtained and the intercept is $\ln \frac{A R}{\beta E}$, so the activation energy $E$ and frequency factor $A$ are obtained.

\section{RESULTS AND DISCUSSION}

\subsection{Combustion characteristic curve}

The TG and DTG curves of the polyol waste liquor combustion and pyrolysis processes, as measured by the thermogravimetric analyzer, are shown in Fig. 3. The combustion reaction data for the plant-derived polyol waste liquor are summarized in Table 1. The combustion characteristic curves of the polyol waste liquor show that the combustion process can be considered in four stages, which are evaporation, pyrolysis, combustion, and inorganic salt reaction. These processes are similar to those that occur during black liquor combustion in the pulp and paper industry, and four fluctuating peaks are evident during the reaction process.

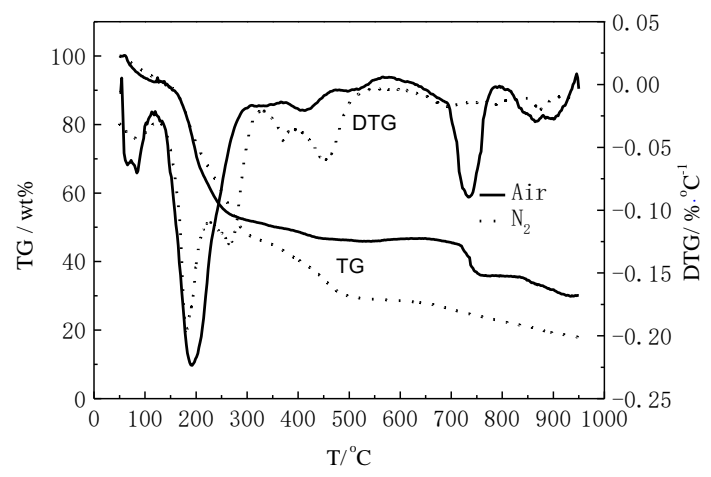

Fig. 3. Characteristic curves for the thermal degradation of the waste liquor

\begin{tabular}{|c|c|c|c|c|}
\hline $\begin{array}{c}\text { Temperature } \\
\text { range, }{ }^{\circ} \mathrm{C}\end{array}$ & $\begin{array}{c}\text { Peak } \\
\text { temperature, } \\
{ }^{\circ} \mathrm{C}\end{array}$ & $\begin{array}{l}\text { Peak } \\
\text { DTG, } \\
\% \cdot{ }^{\circ} \mathrm{C}^{-1}\end{array}$ & $\begin{array}{l}\text { Weight } \\
\text { loss } \\
\text { ratio, \% }\end{array}$ & $\begin{array}{c}\text { Final solid } \\
\text { conversion, } \\
\%\end{array}$ \\
\hline $50-120$ & 84 & 0.0704 & 7.51 & \multirow{5}{*}{69.86} \\
\hline $120-300$ & 192 & 0.2236 & 40.40 & \\
\hline $300-600$ & 1 & 1 & 6.52 & \\
\hline $600-800$ & 733 & 0.0896 & 9.80 & \\
\hline $800-950$ & 871 & 0.0286 & 5.63 & \\
\hline
\end{tabular}

Table 1. Reaction data for waste liquor combustion 
The evaporation process starts when heating from ambient temperature to $120{ }^{\circ} \mathrm{C}$. The DTG curve exhibits a small fluctuation peak, and a peak appears at $84{ }^{\circ} \mathrm{C}$, indicating that the free moisture in the waste liquor has largely evaporated, and the weight loss ratio is $7.51 \%$ after the evaporation process has completed. The pyrolysis process can be separated into two stages, namely the first stage of pyrolysis $\left(120\right.$ to $\left.300{ }^{\circ} \mathrm{C}\right)$ and the second stage of pyrolysis $\left(300\right.$ to $600{ }^{\circ} \mathrm{C}$ ). The pyrolysis process is the main reaction stage and the weight loss ratio on completion accounts for $46.92 \%$ for the change in weight. The largest fluctuation peak of the entire pyrolysis process occurs during the first stage of the reaction. The peak temperature was $192{ }^{\circ} \mathrm{C}$, and the peak weight loss rate was $0.2236 \% \cdot{ }^{\circ} \mathrm{C}^{-}$ ${ }^{1}$. The weight loss ratio of the first stage also was the largest, accounting for $40.4 \%$ of the total weight of the droplet. During the first stage of pyrolysis, the rate of weight loss is large, and the reaction speed is rapid. The main mechanism of weight loss is the loss of a small amount of remaining free moisture, the water of crystallization and decomposition of weak aliphatic carboxylic acids in the waste liquor. The weight loss curve for the second stage of pyrolysis is very gentle and there is no fluctuation peak. This stage is mainly associated with decomposition of the relatively strong chemical bonds and the partial breakdown of the macromolecular organic matter in the aliphatic carboxylic acid, so the reaction rate is slower than the first stage and a higher reaction temperature is required.

After the heating temperature reaches $600^{\circ} \mathrm{C}$, and as the temperature increases, the ignition temperature range of the waste liquor is reached, and the material commences the combustion process. A large fluctuation peak, therefore, appears in the DTG curve. The temperature peaks at $733{ }^{\circ} \mathrm{C}$, and a peak weight loss rate of $0.0896 \%{ }^{\circ} \mathrm{C}^{-1}$ is observed. After the pyrolysis process, a small amount of macromolecular organic matter and carbon remain from the waste liquor. In the presence of combustion air, a combustion reaction occurs, which is intense, but most of the organic matter is decomposed during the pyrolysis process. Little more combustible is available so the weight loss rate and weight loss ratio $(9.8 \%)$ are lower than during the first stage of pyrolysis. After the heating temperature reaches $800{ }^{\circ} \mathrm{C}$, the inorganic salt reaction process commences. The reaction process was slow, but a gentle weight loss fluctuation peak appeared. The peak temperature was $871^{\circ} \mathrm{C}$, and the peak weight loss rate was $0.0286 \%{ }^{\circ} \mathrm{C}^{-1}$. The weight loss ratio of the inorganic salt reaction process was $5.63 \%$, which is relatively small. The melting temperature of sodium carbonate is $851{ }^{\circ} \mathrm{C}$, so raising the temperature to over $1000{ }^{\circ} \mathrm{C}$ will result in a slow decomposition

reaction $4 \mathrm{Na}_{2} \mathrm{CO}_{3}(\mathrm{l}) \stackrel{\Delta}{\rightarrow} \mathrm{Na}_{2} \mathrm{O}+\mathrm{CO}_{2} \uparrow[24]$. The maximum heating temperature of the test was $950{ }^{\circ} \mathrm{C}$, so the inorganic salt reaction process is mainly associated with the following two chemical reactions. Chemical reaction Eq. 5 and Eq. 6 are relatively slow, and the two reactions cross over, making the rate of weight loss very flat [25].

$$
\begin{aligned}
& 4 \mathrm{Na}+2 \mathrm{C}+3 \mathrm{O}_{2} \rightarrow 2 \mathrm{Na}_{2} \mathrm{CO}_{3}(\mathrm{l}) ; \\
& \mathrm{Na}_{2} \mathrm{CO}_{3}(\mathrm{l})+2 \mathrm{C}(\mathrm{s}) \rightarrow 2 \mathrm{Na}+3 \mathrm{CO} \uparrow .
\end{aligned}
$$

Comparing the characteristic curves in Fig. 1 from the air and nitrogen atmospheres, it is observed that the atmosphere has an important influence on the reaction process of the polyol waste liquor. Whereas there are four reaction processes in an air atmosphere, only three processes of evaporation, pyrolysis, and inorganic salt reaction are observed under a nitrogen atmosphere. When the heating temperature is less than $300{ }^{\circ} \mathrm{C}$, the two environments have similar characteristic curves, indicating that the oxygen in the air has little effect on the evaporation process or the first stage of pyrolysis. When the heating temperature is in the range of $300-600{ }^{\circ} \mathrm{C}$, a significant wave peak was evident under the nitrogen atmosphere, whereas the presence of oxygen causes the surface of the waste liquor to form an oxide film in the air atmosphere, and that affects the pyrolysis process such that it does not exhibit fluctuation peaks. The weight loss ratio under the second stage of pyrolysis under nitrogen is significantly greater than in the air atmosphere. When the heating temperature had been raised higher than $600{ }^{\circ} \mathrm{C}$, the combustion reaction will occur in the air atmosphere. By contrast, in the nitrogen atmosphere, the weight loss curve drops sharply and the weight loss curve changes gently. When the heating temperature is raised higher than $800{ }^{\circ} \mathrm{C}$, the inorganic salt reaction process exhibits a small fluctuation peak in both atmospheres, but the reaction is made more intense in the air atmosphere, due to the participation of oxygen in the reaction.

Comparing the total weight loss ratios under the two atmospheres, it was found that the total weight loss rate at the final temperature in the air atmosphere was smaller than that under the nitrogen atmosphere, indicating that oxygen in the air participates in the reaction, so reaction Eq. 5 predominates, resulting in an increase in the final product mass ratio [26].

\subsection{Ignition characteristics}

The ignition temperature refers to the temperature at which the carbon begins to burn during pyrolysis of the waste liquor and is an important parameter for characterizing the combustion characteristics of the liquor [27].

The ignition temperature of the plant-derived polyol waste liquor was determined using the TG-DTG method. On the DTG curve exhibited a peak at point a. A vertical line through point a intersects the TG curve at inflection point $b$, as shown in Fig. 4.

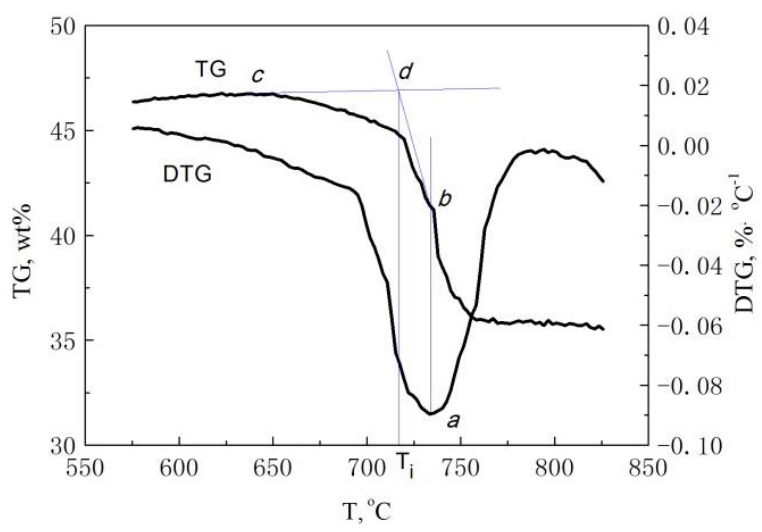

Fig. 4. Ignition temperature of waste liquor 
When the initial slope tangent (through the point c) of the TG curve intersects the tangent of point $b$ of the TG curve, it gives point $\mathrm{c}$, which is the ignition temperature, $T i$. The ignition temperature $T i$, is an important factor that determines the stability of combustion of the waste liquor [28, 29].

Fig. 4 shows that the ignition temperature of the plant chemical polyol waste liquor was $718^{\circ} \mathrm{C}$, which is higher than most pulp black liquor, indicating that it is not easy to burn [27]. Volatilization of plant-derived polyol waste liquor is concentrated during the first stage of pyrolysis. During the second stage of pyrolysis, the decomposition of the macromolecular organic matter is slow, and a high temperature is required, which results in an increase in the carbon combustion temperature.

\subsection{Combustion dynamics parameters}

It can be seen from the combustion weight loss curve that the main weight loss is divided into three stages, and the temperature ranges are $150-260{ }^{\circ} \mathrm{C}, 720-760{ }^{\circ} \mathrm{C}$, and $840-900^{\circ} \mathrm{C}$. The activation energy and frequency factor values are two important parameters for characterizing the reaction dynamics, and the two parameters determine the rate of chemical reaction $[30,31]$.

To calculate the activation energy $E$, and the value of the frequency factor $A$ at different heating rates for the three reaction zones, different values of $\mathrm{n}$ are substituted into Eq. 2 and Eq. 3. When $n=1.2$, the plot of against $1 / T$ is basically a straight line, as shown in Fig. 5, and the activation energy $E$ and frequency factor $A$ are obtained at different temperature ranges, as listed in Table 2.

Table 2. $E, A, R^{2}$ values for different heating rates and temperature ranges

\begin{tabular}{|c|c|c|c|c|c|}
\hline Temperature, ${ }^{\circ} \mathrm{C}$ & \multicolumn{2}{|c|}{$E, \mathrm{KJ} \cdot \mathrm{mol}^{-1}$} & \multicolumn{2}{|c|}{$A, \mathrm{~min}^{-1}$} & $R^{2}$ \\
\hline $170-300$ & E1 & 32.2 & A1 & 293 & 0.954 \\
\hline $390-475$ & E2 & 113.2 & A2 & $2.3 \cdot 10^{5}$ & 0.953 \\
\hline $840-900$ & E3 & 71.0 & A3 & 499 & 0.972 \\
\hline
\end{tabular}

From the calculation results presented in Table 2, at the same heating rate, the order of the activation energy values is $E 1<E 3<E 2$ and the order of the frequency factor values is $A 1<A 3<A 2$. The activation energy and frequency of the combustion process and the inorganic salt reaction process are significantly higher than those of the pyrolysis process. The $E / A$ values for the waste liquor pyrolysis process is the smallest, and the peak weight loss rate is the largest, mainly because there are a large number of organic substances with weak chemical bonds in the waste liquor, which are easily decomposed. The $E / A$ value of the combustion process is the largest, indicating that the carbon in the waste liquor requires more heat. The $E / A$ value of the inorganic salt reaction process is lower than that of the combustion processes and should be related to the decomposition of the alkali sodium salts in the waste liquor.

Compared to paper pulp black liquor, the combustion activation energy of the plant-derived polyol waste liquor is similar to that of the straw pulp black liquor, which is higher than that of other pulp black liquors, indicating that the polyol waste liquor is not easy to burn [27].

\subsection{Analysis of the combustion process}

The waste liquor droplet combustion process was studied in the vertical tube furnace and the combustion process was recorded by a high-speed camera. The mass of waste liquor droplets in the test was $10 \mathrm{mg}$ and the furnace temperature was set sequentially to $600{ }^{\circ} \mathrm{C}, 700{ }^{\circ} \mathrm{C}, 800{ }^{\circ} \mathrm{C}$, $900{ }^{\circ} \mathrm{C}$, and $1000^{\circ} \mathrm{C}$. The images presented in Table 3 are screenshots of the waste liquor droplet reaction process at each temperature.

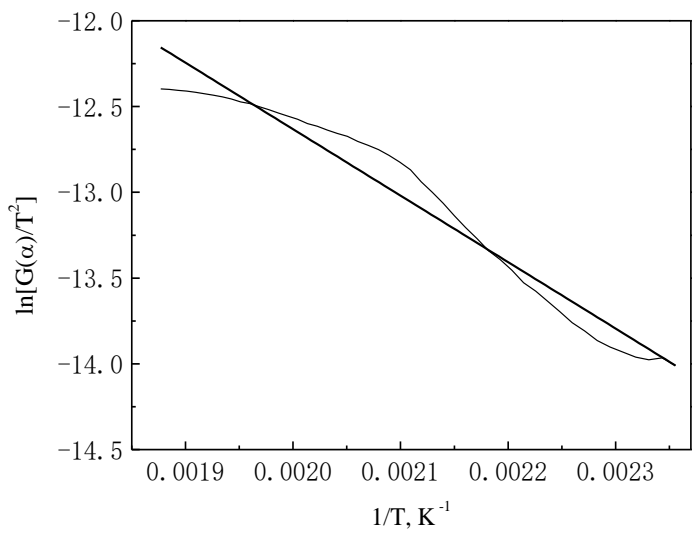

a

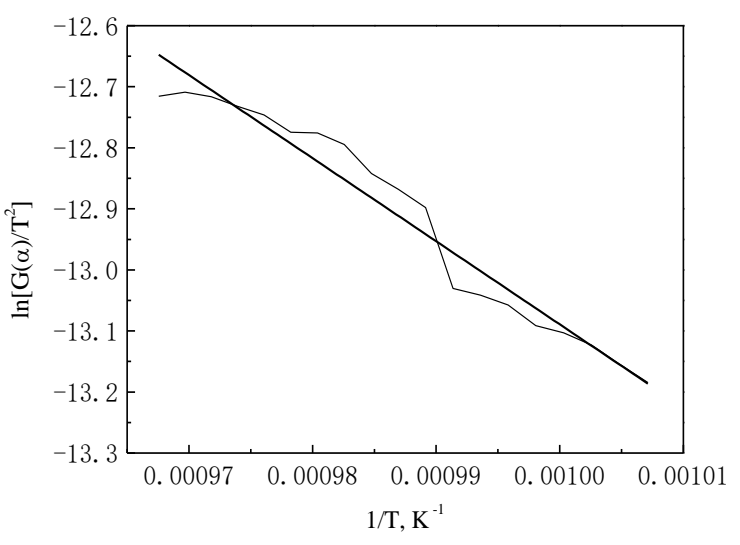

$\mathrm{b}$

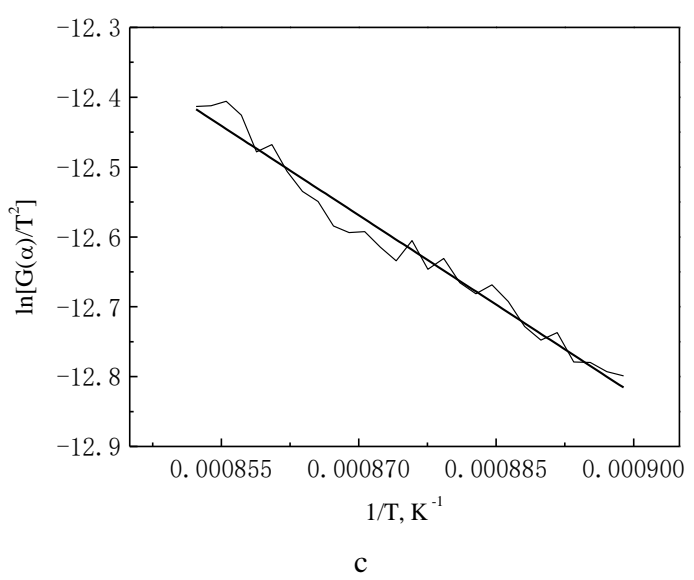

Fig. 5. Linear fit lines at different temperature ranges: $\mathrm{a}-150$ to $260^{\circ} \mathrm{C} ; \mathrm{b}-720$ to $760^{\circ} \mathrm{C} ; \mathrm{c}-840$ to $900^{\circ} \mathrm{C}$

Comparing the combustion process of plant-derived polyol waste liquor droplets at the five test temperatures, it was found that the waste liquor had four specific stages: evaporation, pyrolysis, combustion, and inorganic salt reaction. The waste liquor droplets burned very strongly in 
the furnace. The overall reaction time observed was $8-12 \mathrm{~s}$. From the reaction process of the waste liquor droplets as recorded by the camera, the evaporation process of the liquid droplets was very short and the volume expansion of the droplets during the evaporation process was small; soon the liquid droplets begin to boil and enter the liquefaction condition with intense boiling state; then the volatilization phase occurs, with a very rapid expansion in the droplet volume. No burning flare was observed under the condition of $600{ }^{\circ} \mathrm{C}$, but the flare was very evident at $700{ }^{\circ} \mathrm{C}$. After the visible light disappears, the volume of the waste particle begins to shrink, and the inorganic salt reaction process takes place at $900{ }^{\circ} \mathrm{C}$ and $1000{ }^{\circ} \mathrm{C}$. Especially at $1000{ }^{\circ} \mathrm{C}$, the waste liquor residue becomes turns whitish in color as it approaches the furnace temperature.

From these results of the vertical tube furnace experiment, it was concluded that the ignition temperature of the waste liquor droplets was estimated to be between $600{ }^{\circ} \mathrm{C}$ and $700{ }^{\circ} \mathrm{C}$, which differed from the ignition temperature as determined by the TG-DTG method. The vertical tube furnace tests and the thermogravimetric analyzer results were very different. The vertical tube furnace was pre-set to the desired temperature, and the waste liquor is introduced into the furnace and is heated rapidly. The volatile matter is concentrated and precipitated in a short time, around the surface of the droplet. In the presence of high temperature environment and air, the volatiles first ignited and then burned. In the screenshots shown in Table 3, the bright and long flames also were observed, while in the thermogravimetric analyzer the process was slow. During the heating and pyrolysis process, the volatile matter is precipitated slowly, and no aggregation zone is formed near the droplets, which therefore cannot reach the concentration and temperature required for combustion. When heated to $718{ }^{\circ} \mathrm{C}$, carbon ignition occurs, but this is different to the ignition of the volatiles in the vertical tube furnace, which occurs first [32].

Table. 3. Photographs of the waste liquor droplet reaction process in the vertical tube furnace under air

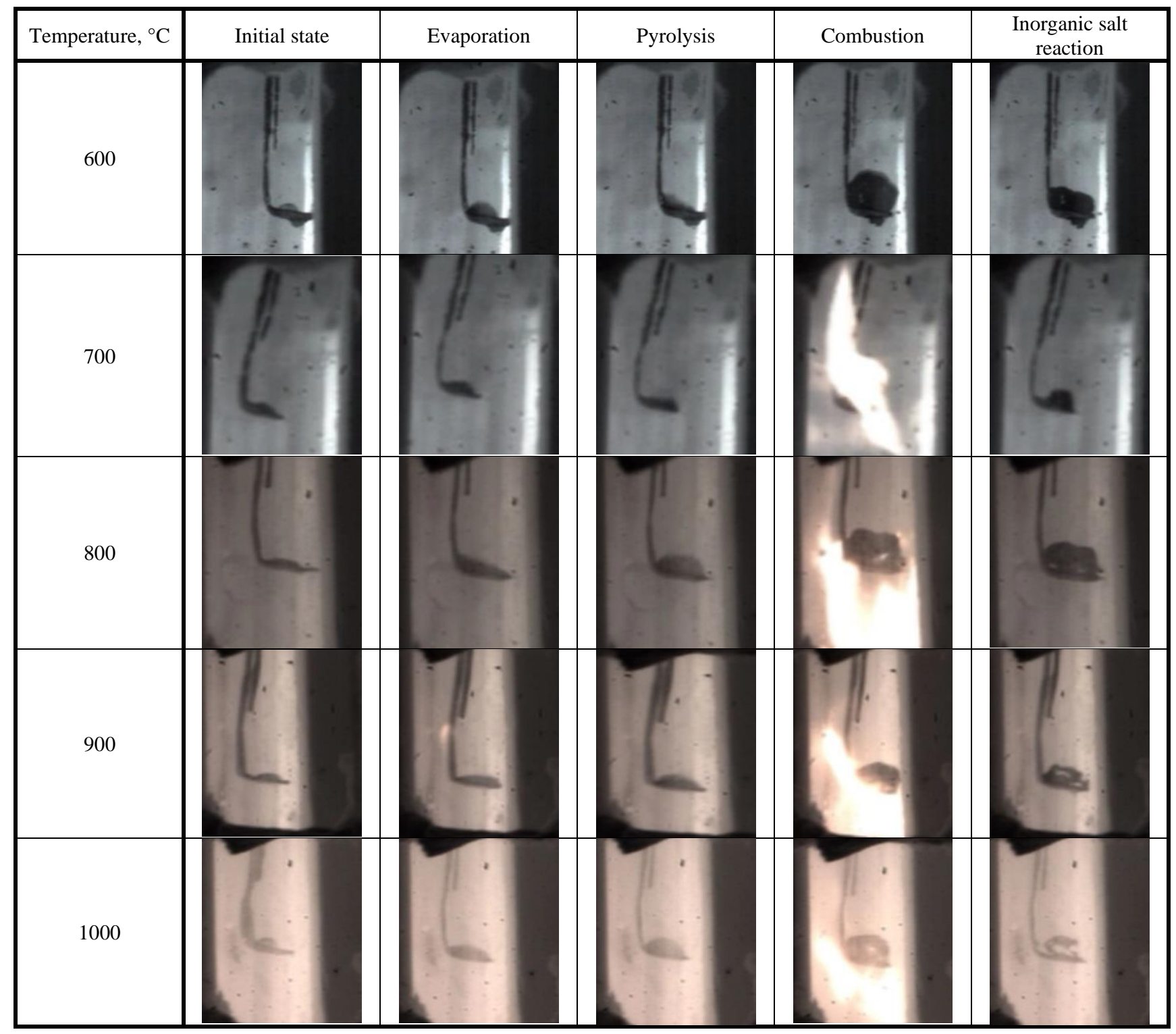




\section{CONCLUSIONS}

1. Four processes were observed during the combustion of plant-derived polyol waste liquor. These were evaporation, pyrolysis, combustion and then calcining of the inorganic salts. Each process has a weight loss fluctuation peak. The peak weight loss rate in the pyrolysis process was the largest and that during the inorganic salt calcining process was the smallest.

2. Of the four processes of the combustion reaction of plant-derived polyol waste liquor, the weight loss ratio of the pyrolysis process was the largest, and the weight loss ratio of the inorganic salt reaction process was the smallest. Oxygen in the air participates in the calcination of inorganic salts, making the total weight loss of waste liquor in nitrogen atmosphere much higher than that in an air atmosphere.

3. The ignition temperature of the waste liquor as determined from the TG-DTG method was $718^{\circ} \mathrm{C}$, whereas the ignition temperature observed in the vertical tube furnace experiment was between $600{ }^{\circ} \mathrm{C}$ and $700{ }^{\circ} \mathrm{C}$. The reason for this apparent discrepancy is that the heating method of the waste liquor sample in the thermogravimetric analyzer and in the vertical tube furnace is different. The temperature determined from the TG-DTG method is the ignition temperature for carbon combustion, whereas the temperature observed in the vertical tube furnace is the ignition temperature of the volatiles generated by pyrolysis.

4. The dynamic parameters for combustion of the waste liquor were calculated using the Coats-Redfern method and the reaction order of the waste liquor combustion was 1.2. The activation energy and frequency factor of the waste liquor pyrolysis process were the smallest and the reaction was the most intense. The activation energy and frequency factor of the inorganic salt reaction process were smaller than those of the combustion process, indicating that the alkali metal, sodium, has an important influence on the reaction process.

5. The results of the DTG and vertical tube furnace tests have demonstrated conclusively that the waste liquor from plant-derived polyol production can be utilized in much the same way as is undertaken with conventional black liquor combustion in pulp and paper processing as a substantial source of energy (perhaps for electric power production) and simultaneous recovery of valuable calcined salts.

\section{Acknowledgments}

Supported by the China Natural Science Foundation of Innovative Research Group (51421063).

\section{REFERENCES}

1. Basu, P. Biomass gasification and pyrolysis: practical design and theory, Beijing: Science Press 2011: pp. 4-16.

2. Kamm, B., Gruber, P.R., Kamm, M. BiorefineresIndustrial Processes and Products Ullmann's Encyclopedia of Industrial Chemistry 2007: pp. 139-164. https://doi.org/10.1002/14356007.104_101

3. Zhu, Y.Q., Romain, C., Williams, C.K. Sustainable polymers from renewable resources Nature $540(7633)$ 2016: pp. $354-362$. https://doi.org/10.1038/nature21001

4. Bao, N.N. Study on the Application of Corn Biological Chemical Glycol, Changchun University of Technology, 2011: pp.1-4.

5. National Development and Reform Commission. Independent innovation, technology breakthrough - Jinlin Dacheng Group has made revolutionary progress on Biochemical technology, 2009.

http://www.ndrc.gov.cn/fzgggz/gyfz/gyfz/200912/t20091201 _795186.html

6. Cruz-Aldaco, K., Flores-Loyola, E., AguilarGonzález, C.N., Burgos, N., Jiménez, A. Synthesis and Thermal Characterization of Polyurethanes Obtained from Cottonseed and Corn Oil-Based Polyols Journal of Renewable Materials 4 (3) 2016: pp. 178-184. https://doi.org/10.7569/JRM.2016.634107

7. Wang, D.W., Hu, C.W., Tang, L., Wang, B.H. Combustion method of biochemical polyol boiler, China Patent No.: CN103486573A, 2014.

8. Gullichsen, J., Fogelholm, C.J. Chemical Pulping, Finland: Fapet Oy, 2000: pp. B16-95.

9. Hupa, M., Solin, P., Hyoty, P. Combustion behavior of black liquor droplets Tappi Press Book 3 1986: pp. 335-344.

10. Backman, R., Frederick, W.J., Hupa, M. Basic studies on black-liquor pyrolysis and char gasification Bioresource Technology $46(1-2)$ 1993: pp. 153-158. https://doi.org/10.1016/0960-8524(93)90067-1

11. Adams, T.N., Frederick, W.J., Grace, T.M., Hupa, M., Iisa, K., Jones, A.K., Tran, H. Kraft Recovery Boilers Tappi Press 1997: pp. 132-136.

12. Empie, H.J., Frederick, J.W., Grace, T.M., Horton, R.R., Nichols, K.M., Medvecz, P.J., Verrill, C.L. Black liquor combustion-validated recovery boiler modeling capability US DOE Report 1991: pp. 18-20.

13. Larsson, A., Nordin, A., Backman, R., Warnqvist, B., Eriksson, G. Influence of Black Liquor Variability, Combustion, and Gasification Process Variables and Inaccuracies in Thermochemical Data on Equilibrium Modeling Results Energy \& Fuels 20 (1) 2006: pp. $359-363$. https://doi.org/10.1021/ef050181w

14. Nassar, M. Thermal Behavior of Bagasse Kraft Black Liquor Energy Sources 25 (8) 2003: pp. 837-844. https://doi.org/10.1080/00908310390215720

15. Engblom, M. Modeling and Field Observations of Char Bed Processes in Black Liquor Recovery Boilers, Turku: Abo Akademi University, 2010: pp.1-4.

16. Järvinen, M.P., Zevenhoven, R., Vakkilainen, E., Forssén, M. Black Liquor Devolatilization and Swelling - A Detailed Droplet Model and Experimental Validation Biomass \& Bioenergy 24 (6) 2003: pp. 495-509. https://doi.org/10.1016/s0961-9534(02)00151-4

17. Roberts, W., Lu, H., Ip, E., Baxter, L.L. Black Liquor Particle and Droplet Reactions: Experimental and Model Results 45th Anniversary International Recovery Boiler Conference Lahti, Finland, 2009: pp. 57-100. https://doi.org/10.13140/2.1.4273.7923

18. Leong-Teng, L., Baxter, L.L., Mackrory, A.J., Tree, D.R. Surface Temperature and Time - Dependent Measurements of Black Liquor Droplet Combustion AIChE Journal 54 (7) 2008: pp. 1926-1931. https://doi.org/10.1002/aic.11504 
19. Alén, R., Rytkönen, S., Mckeough, P. Thermogravimetric Behavior of Black Liquors and Their Organic Constituent Journal of Analytical \& Applied Pyrolysis 31 (94) 1995: pp. $1-13$.

https://doi.org/10.1016/0165-2370(94)00811-E

20. Malkavaara, P., Alén, R., Kolehmainen, E. Multivariate Correlation Between 13C And 31P NMR Spectral Data on Dissolved Lignin and the Combustion Properties of Kraft Black Liquor Magnetic Resonance in Chemistry 37 (6) 1999: pp. $407-412$. https://doi.org/10.1002/(SICI)1097458X(199906)37:6<407::AID-MRC475>3.0.CO;2-S

21. Hu, R.Z., Shi, Q. Zh. Thermal analysis Kinetics, Beijing: Science Press, 2001: pp. 127-131.

22. Wu, Sh.B., Tan, Y., Guo, Y.L., Liu, J.Y. Thermogravimetric Properties of Black Liquor and Corresponding Kinetic Analysis Journal of South China University of Technology 6 2007: pp. 59-63. https://doi.org/10.1016/S1872-5791(07)60010-4

23. Zhao, W.D., Liu, J.Zh., Zhang, B.Zh., Zhou, J.H., Cen, K.F. Kinetic Parameters of Petroleum Coke Water Slurry Combustion by Different Methods Proceedings of the CSEE 28 (7) 2008: pp. 55-60. https://doi.org/10.3321/j.issn:0258-8013.2008.17.010

24. Yan, K.Zh., Guo, Y.X., Liu, D.D., Ma, Zh.B., Cheng, F.Q. Thermal Decomposition and Transformation Mechanism of Mullite with the Action of Sodium Carbonate Journal of Solid State Chemistry 265 2018: pp. 326-331. https://doi.org/10.1016/j.jssc.2018.06.014

25. Saw, W.L., Nathan, G.J., Ashman, P.J., Hupa, M.M. Influence of Droplet Size on the Release of Atomic Sodium from a Burning Black Liquor Droplet in a Flat Flame Fuel 89 (8) 2010: pp. $1840-1848$. https://doi.org/10.1016/j.fuel.2010.04.002

26. Vähäsavo, N., Demartini, N., Engblom, M., Brink, A., Hupa, M.M. The Fate of Char Nitrogen in Black Liquor Combustion-Cyanate Formation and Decomposition Industrial \& Engineering Chemistry Research 54 (11) 2015: pp. $2831-2842$. https://doi.org/10.1021/ie503450r

27. Wang, Y.Y. Combustion Behavior of Straw Black Liquor China Pulp and Paper 18 (5) 1999: pp. 55-58. https://doi.org/10.3969/j.issn.0254-508X.1999.05.013

28. Xia, K.P. Experimental Research on the Characteristics of Coal Pyrolysis and Gasification at High Temperature and High Pressure Wuhan: Huazhong University of Science and Technology, 2006: pp. 14-19. https://doi.org/10.7666/d.d045120

29. Zhou, J., Zhang, H., Lü, J.F. Study on Combustion on Characteristics of a Petroleum Coke at Different Heating Rates by Using Thermogravimetry Coal Conversion 29 (2) 2006: pp. 39-43. https://doi.org/10.3969/j.issn.1004-4248.2006.02.010

30. Zhang, J. Analysis of Activation Energy and Frequency Factor Boiler Manufacturing 4 1996: pp. 5-8.

31. Surahmanto, F., Saptoadi, H., Sulistyo, H., Rohmat, T.A. Investigation of The Slow Pyrolysis Kinetics of Oil Palm Solid Waste by the Distributed Activation Energy Model Biofuels 2017: pp. 1-8. https://doi.org/10.1080/17597269.2017.1387750

32. Orlovskaya, S.G., Zuy, O.N., Liseanskaia, M.V. Influence of Gas Temperature on Ignition, Burning and Extinction of Carbon Particles-Gas Suspension Journal of Physics: Conference Series 891 2017: pp. 012234. https://doi.org/10.1088/1742-6596/891/1/012234

(C) Wang et al. 2021 Open Access This article is distributed under the terms of the Creative Commons Attribution 4.0 International License (http://creativecommons.org/licenses/by/4.0/), which permits unrestricted use, distribution, and reproduction in any medium, provided you give appropriate credit to the original author(s) and the source, provide a link to the Creative Commons license, and indicate if changes were made. 